\title{
Renal trauma: a 5-year retrospective review in single institution
}

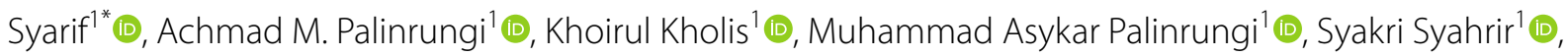
Reinaldo Sunggiardi ${ }^{2}$ and Muhammad Faruk ${ }^{2}$ (D)

\begin{abstract}
Background: Renal trauma occurs in up to $5 \%$ of all trauma cases and accounts for $24 \%$ of abdominal solid organ injuries. Renal trauma management has evolved over the past decades, and current management is transitioning toward more conservative approaches for the majority of hemodynamically stable patients. The objective of this study was to analyze the mechanism of injury, management, and outcome in renal trauma.

Methods: Patients diagnosed with renal trauma in Makassar, Indonesia, from January 2014 to December 2018 were identified retrospectively by the ICD-10 code. Data were collected from medical records. Imaging was classified by radiologists. Variables analyzed included age, sex, mechanism of injury, degree of renal trauma, related organ injury, management, and outcome.

Results: Out of the 68 patients identified, the average age was $23.9 \pm 0.6$ years, and most were male (83.8\%). Blunt trauma accounted for $89.7 \%$ of all cases. The most common renal injuries were grade IV (42.6\%), and $14 \%$ of the cases had no hematuria. Most patients were treated with non-operative management (NOM). Nephrectomy was performed in $16.2 \%$ of cases, and $5.9 \%$ of cases underwent renorrhaphy. It was found that $58.8 \%$ of cases had isolated renal trauma, and the overall mortality rate (2.9\%) was due to related injuries.

Conclusions: The majority of blunt and penetrating renal trauma cases that are hemodynamically stable have a good outcome when treated with NOM. The presence of injury in other important organs both intra- and extraabdominally aggravates the patient's condition and affects the prognosis.
\end{abstract}

Keywords: Renal trauma, Grading, Non-operative Management

\section{Background}

Anatomically, the kidneys are well protected by the strong lumbar muscles, vertebra, ribs, and abdominal viscera on the anterior side. However, the kidneys are the genitourinary organs that are most often traumatized [1, 2]. Kidneys with pathological conditions such as hydronephrosis or malignancy are more susceptible to rupture due to minor trauma [2]. The incidence of renal trauma is around 245,000 cases each year worldwide [3, 4]. Renal

\footnotetext{
*Correspondence: syarifbakri@hotmail.com

${ }^{1}$ Division of Urology, Department of Surgery, Faculty of Medicine, Hasanuddin University, Jalan Perintis Kemerdekaan KM 11,

Makassar 90245, Indonesia

Full list of author information is available at the end of the article
}

trauma occurs in up to $5 \%$ of all trauma cases, accounts for $24 \%$ of abdominal solid organ injury, and was the third most commonly injured organ due to abdominal trauma after the spleen and liver [3,5-10].

Blunt trauma to the abdomen, flank, or back is the most common mechanism of injury [1]. Blunt trauma is reported to be the cause of the majority of cases (80-95\% of all renal trauma) and mostly occurs due to traffic accidents $[6,11]$. However, in the military community and large cities, the prevalence of penetrant renal trauma can reach $20 \%$ or more [8]. Many blunt renal traumas are in the low-grade classification, and $80-85 \%$ of these cases can be treated with non-operative management (NOM) [11]. Renal trauma is often 
associated with injury to other major organs [5] and occurs in $3 \%$ of patients who are hospitalized due to trauma [10].

The most common grading for renal trauma is that of the American Association for the Surgery of Trauma (AAST), as shown in Table 1. This classification is a predictor for morbidity in blunt and penetrating renal injury and for mortality in blunt injury. The AAST grading (grade I to grade V) has a statistically significant correlation with the need for operative management (from 0 to $93 \%$ ) and the risk for nephrectomy (0-86\%) [12]. The treatment for renal trauma consists of one or more of the following: conservative management, minimally invasive intervention (e.g., angioembolization), placement of an ureteral stent, or open surgical intervention [13].

The purpose of this study was to analyze the demographics and characteristics of renal trauma in our institution.

\section{Methods}

We looked at the characteristics and descriptions of renal trauma cases in Makassar, Indonesia, for the 5 years from January 2014 to December 2018. We conducted a descriptive study with retrospective analysis by describing data on patients who have experienced renal trauma with ICD-10 code S-37.0 based on medical records at four teaching hospitals at our institution in Makassar, Indonesia. The data review included demographics, mechanisms of injury, clinical characteristics, laboratory, and radiology result at the time of admission. Cases that had insufficient of information or did not have multi-slice computed tomography (MSCT) when diagnosed were excluded from the study. Descriptive statistics were analyzed for the population characteristics and outcomes using SPSS
21 for Windows (IBM Corp. Released 2012. IBM SPSS Statistics for Windows, version 21.0. Armonk, NY: IBM Corp.).

\section{Results}

In this hospital-based observational retrospective study, 68 cases of trauma involving renal injury were obtained, and the patient characteristics are presented in Table 2 . We found that $83.8 \%$ (57 of 68) of the patients were male, and only 11 were female (16.2\%). The age at admission was $23.9 \pm 0.6$ years (range $=5-61$ years), and adolescents with an age range of 11-20 years were the largest age group. Blunt renal trauma was the most common type (89.7\%), with traffic accidents responsible for the majority of mechanisms of injury. Although it seems to fluctuate, there was a tendency for a pattern of increased incidence of renal trauma from year to year with a peak in 2018 reaching 21 cases, which is almost twice that of previous years. The majority of cases (58.8\%) in this study involved the left kidney.

Hematuria (both microscopic and gross) was found in $86 \%$ of all renal trauma. Assessment of the severity of renal trauma refers to recommendations from AAST. Most cases (42.6\%) had grade IV renal trauma, and $77.9 \%$ of them were treated with NOM. High-grade renal trauma is often accompanied by injury to other related intra-abdominal organs (Fig. 1). In this study, most cases (58.8\%) had isolated renal trauma, and the remaining $41.2 \%$ were multiple-trauma patients who had injuries to other major organs (Table 3). Interventions for nephrectomy and renorrhaphy were performed in 11 and 4 of the high-grade renal trauma cases, respectively. The mortality rate was $2.9 \%$ (Fig. 2).

\section{Discussion}

The majority of patients in our study (83.8\%) were male, and a similar situation can be found in other renal trauma studies $[5,6,8,14-16]$. The age at admission was

Table 1 Grading of renal trauma according to the American Association for the Surgery of Trauma (AAST) [14-16]

\begin{tabular}{lll}
\hline Grade & Type of injury & Description of injury \\
\hline I & Contusion & Microscopic or gross hematuria, urologic studies normal \\
II & Hematoma & Subcapsular, non-expanding without parenchymal laceration \\
& Laceration & Non-expanding perirenal hematoma confirmed to renal retroperitoneum \\
LII & $<1.0 \mathrm{~cm}$ parenchymal depth of renal cortex without urinary extravasation \\
& Laceration & $>1.0 \mathrm{~cm}$ parenchymal depth of renal cortex without collecting system rupture or \\
& Vascular & Parenchymal laceration extending through renal cortex, medulla, and collecting system \\
Laceration & Main renal artery or vein injury with contained hemorrhage \\
& Vascular & Completely shattered kidney \\
& & Avulsion of renal hilum which devascularizes the kidney
\end{tabular}


Table 2 Characteristics of renal trauma

\begin{tabular}{|c|c|c|}
\hline & Number of cases & $\%$ \\
\hline \multicolumn{3}{|l|}{ Years } \\
\hline 2014 & 13 & 19.1 \\
\hline 2015 & 10 & 14.7 \\
\hline 2016 & 11 & 16.2 \\
\hline 2017 & 13 & 19.1 \\
\hline 2018 & 21 & 30.9 \\
\hline \multicolumn{3}{|l|}{ Age group (years) } \\
\hline $1-10$ & 5 & 7.4 \\
\hline $11-20$ & 30 & 44.1 \\
\hline $21-30$ & 19 & 27.9 \\
\hline $31-40$ & 4 & 5.9 \\
\hline $41-50$ & 6 & 8.8 \\
\hline $51-60$ & 3 & 4.4 \\
\hline $61-70$ & 1 & 1.5 \\
\hline \multicolumn{3}{|l|}{ Gender } \\
\hline Male & 57 & 83.8 \\
\hline Female & 11 & 16.2 \\
\hline \multicolumn{3}{|l|}{ Renal side } \\
\hline Right & 28 & 41.2 \\
\hline Left & 40 & 58.8 \\
\hline \multicolumn{3}{|l|}{ Mechanism of injury } \\
\hline Traffic accidents & 49 & 72.1 \\
\hline Fall & 10 & 14.7 \\
\hline Fight & 7 & 10.3 \\
\hline latrogenic & 1 & 1.5 \\
\hline \multicolumn{3}{|l|}{ Trauma type } \\
\hline Blunt & 61 & 89.7 \\
\hline Penetrant & 7 & 10.3 \\
\hline \multicolumn{3}{|l|}{ Hematuria } \\
\hline Gross & 31 & 62 \\
\hline Microscopic & 12 & 24 \\
\hline Without hematuria & 7 & 14 \\
\hline \multicolumn{3}{|l|}{ Hemodynamics } \\
\hline Stable & 61 & 89.7 \\
\hline Shock & 7 & 10.3 \\
\hline \multicolumn{3}{|l|}{ AAST grade } \\
\hline । & 17 & 25 \\
\hline$\|$ & 10 & 14.7 \\
\hline III & 6 & 8.8 \\
\hline IV & 29 & 42.6 \\
\hline V & 6 & 8.8 \\
\hline \multicolumn{3}{|l|}{ Management } \\
\hline $\mathrm{NOM}$ & 53 & 77.9 \\
\hline $\mathrm{OM}$ & 15 & 22.1 \\
\hline \multicolumn{3}{|l|}{ Outcome } \\
\hline Good & 66 & 97.1 \\
\hline Poor & 2 & 2.9 \\
\hline
\end{tabular}

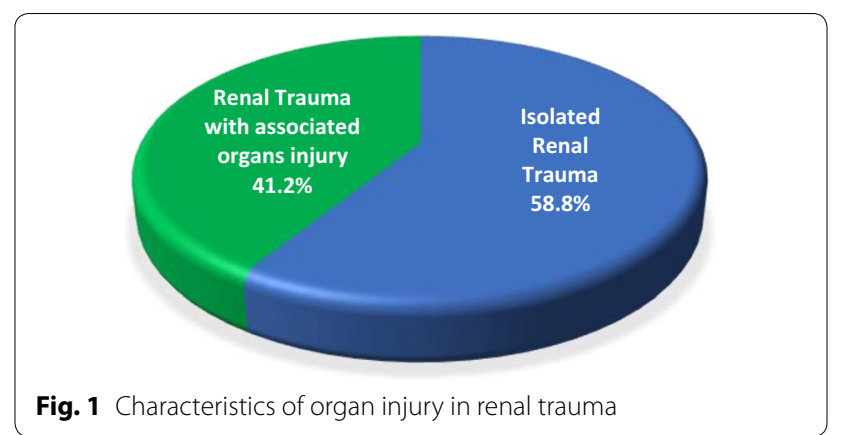

to renal trauma

\begin{tabular}{ll}
\hline Organs & $\begin{array}{l}\text { Number } \\
\text { of cases }\end{array}$ \\
\hline Intra-abdominal & \\
Liver & 7 \\
Spleen & 9 \\
Stomach & 1 \\
Large intestine & 1 \\
Extra-abdominal & \\
Lungs & 4 \\
Ribs & 5 \\
Femur bone & 2 \\
Pelvic bone & 5 \\
Head trauma & 6
\end{tabular}

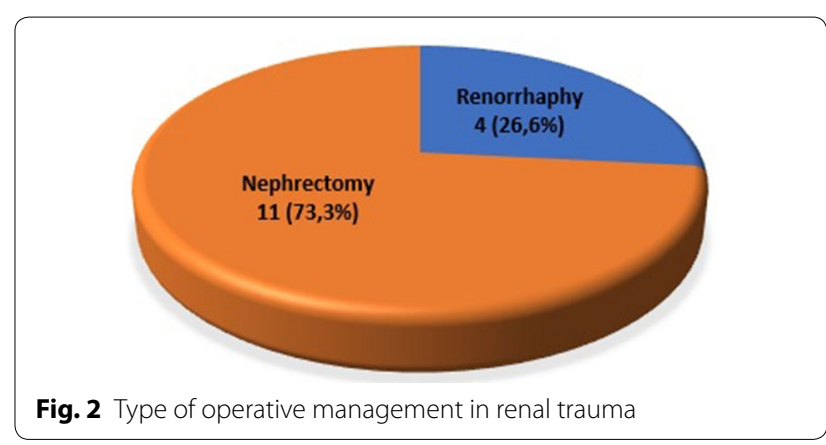

$23.9 \pm 0.6$ years (range $=5-61$ years), and adolescents (age range 11-20 years) were the largest age group (30 cases). In a study by Patel et al., the highest incidence of renal trauma was seen in the 11 to 20 -year-old group (average age of 22.76 years), and almost $80 \%$ of patients were $10-39$ years old [10].

The high incidence in males could be associated with habitual patterns and their role as the backbone of families with a more dominant level of activity rather than females. The majority of men in Indonesia use 
motorbikes as their main transportation, have hobbies in physical sports, and do more outdoor work with a higher risk of workplace accidents. The large number of pediatric renal trauma cases in our review is a matter of its own and requires a holistic approach from various stakeholders. Teenagers and young adults tend to be more aggressive with emotions, which are still unstable, and they often do not pay attention to safety factors, especially in driving. This indirectly affects the high rate of traffic accidents as the main cause of renal trauma in our study. This is consistent with several reviews conducted in various countries showing similar results [6, 10, 15-17].

Collisions of high-speed motor vehicles can cause severe renal trauma because of the rapid deceleration, so in addition to parenchymal lacerations, they can also cause vascular injury. Injuries in the flank area must be considered to have a renal trauma until proven otherwise. Direct transmission of kinetic energy and rapid deceleration put the kidneys at a high risk of injury [1].

Contrary to our study, where blunt trauma was the most common cause $(89.7 \%)$ of renal trauma, in a study by Guareschi et al. [14] in Brazil, the most frequent mechanism was penetrating trauma, which amounted to $84.8 \%$. However, Voelzke and Leddy found that $84 \%$ of renal traumas in adults and $89 \%$ of pediatric renal trauma were a result of blunt trauma, and more than $50 \%$ of traumas were due to motor vehicle accidents [15].

High-grade renal trauma is often associated with injury to other organs. Most of the cases $(58.8 \%)$ in this study had isolated renal trauma, and the remaining $41.2 \%$ had multiple traumas with other organ-related injuries. According to a study conducted by Khan et al., multiorgan involvement occurs in $80 \%$ of patients with penetrating trauma and in $75 \%$ of patients with blunt trauma [6]. As intra-abdominal organs, the liver and spleen are often injured in cases of renal trauma. In addition to their anatomical locations, which are directly adjacent to the kidneys, these two organs are also relatively fixed in the abdominal cavity, so they are susceptible to injury if exposed to direct transmission of kinetic energy or rapid deceleration forces from trauma.

Intra-abdominal hollow organs are often injured if the underlying mechanism is penetrant trauma. In a study by Mangaiyarkarasi et al. [5], the spleen was often injured along with renal trauma. These findings are in line with our study, which showed the spleen is the most common organ injured due to renal trauma (9 cases), followed by the liver ( 5 cases). The presence of multiple traumas and the involvement of intra and extra-abdominal organ injuries affect the patient's hemodynamic condition. There were 2 patients with grade IV renal trauma and 5 patients diagnosed with grade $\mathrm{V}$, who entered a state of hypovolemic shock.
Hematuria and hypotension are two important clinical signs associated with an increased risk of significant renal trauma. The urinalysis provides fast information in patients suspected of having renal parenchymal lacerations; however, it must be adjusted to the clinical context of the patient [6]. The presence of microscopic hematuria ( $>5$ red blood cells per high power field (RBC/HPF)) or gross hematuria is an indicator of suspected urinary tract trauma, including renal trauma. However, the severity of hematuria and grade of renal trauma are not consistently correlated [5, 7]. We found $31(62 \%)$ cases with gross hematuria, $12(24 \%)$ cases of microscopic hematuria, and $7(14 \%)$ cases without hematuria. This is not in line with the research by Maarouf et al., who found that all renal trauma patients had hematuria with gross hematuria in $94.2 \%$, whereas micro-hematuria was found in $5.8 \%$ of cases [16].

We found that the most cases of renal trauma were grade IV ( 29 cases; $42.6 \%$ ), followed by 17 cases (25\%) of grade I, 10 cases (14.7\%) of grade II, and 6 cases (8.8\%) each of grades III and V. The simultaneous presence of other organ injuries, especially in cases of multiple traumas, often affects the management of renal trauma. Rajendra et al. state that around $80-90 \%$ of renal trauma cases have other major organ injuries that require surgical exploration [7].

In a meta-analysis study by Voelzke and Leddy, the majority of blunt and penetrating renal traumas were managed by NOM (94.8\%) [15]. In our study, emergency surgery was done in 15 cases $(22.1 \%)$ of high-grade renal trauma. Six cases had hemodynamics that were unstable at the time of admission, and resuscitation had been carried out to maintain systolic blood pressure above $90 \mathrm{mmHg}$ before the intervention was performed. Renorrhaphy was performed on 4 cases of grade IV renal trauma. The nephrectomy rate in our study was high (16.2\%), including 7 cases of grade IV and 4 cases of grade $\mathrm{V}$ renal trauma, respectively. The majority of renal trauma cases can be treated non-operatively, but grade IV and V renal trauma more often requires exploration.

Mangaiyarkarasi stated that significant renal trauma requiring intervention was found in $5.4 \%$ of all cases [5]. In a study involving 206 cases of renal trauma, the NOM could only be adopted in $181(87.8 \%)$ cases. Nephrectomy was most commonly performed (68\%), while renorrhaphy and angioembolization were performed in $32 \%$ of cases. Of the 17 nephrectomies, 6 (35.3\%) were grade IV, and 11 (64.7\%) were grade $\mathrm{V}$ [15].

There is general consensus about the management with NOM in low-grade renal trauma; however, there are still debates and disagreements about the management of high-grade renal trauma. There are a large number of case reports and evaluations about the success of NOM 
in blunt and penetrant renal trauma in certain selective cases, and there has been a gradual shift in management approach [6, 7]. Usually, exploration of high-grade renal trauma inevitably leads to nephrectomy, and many experts recommend NOM with very many reports of satisfactory results. However, the decision must consider the associated organ morbidity and the right criteria for selecting patients [16]. Surgical intervention is performed on patients with hemodynamic instability (refractory to blood transfusions), persistent bleeding (hematuria or increased hematoma size), or those suspected of having a vascular injury [9].

There are some complications due to renal trauma, and urinoma formation is the most common, occurring in $1-7 \%$ of all cases. Urinary extravasation resolves spontaneously in $76-87 \%$ of cases. Interventions may be needed if there is a continuous leak or urine collection. Retrograde insertion of stents or percutaneous nephrostomy usually helps the resolution process [7]. There were 3 cases in our study where intra-vesical blood clot evacuation via cystoscopy was performed, and in 1 case, a ureteral stent was inserted into a patient who underwent NOM with good renal function outcomes.

In our study, there were two death cases. One of these patients died before intervention due to severe head injury with Glasgow coma scale (GCS) 6, which was also aggravated by the presence of segment VI liver lacerations. The other patient who died had peritonitis and sepsis due to penetrating trauma that passed through the left kidney, descendent colon, and stomach. It even tore the diaphragm and was coupled with uncontrolled comorbid diabetes mellitus. Even though the injury had been successfully repaired (renorrhaphy), $6 \mathrm{~h}$ after, the patient came to the emergency department. Therefore, our study found no mortality due to the direct impact of isolated renal trauma. In a meta-analysis study by Mingoli et al., in blunt trauma and penetrating renal trauma, a higher mortality rate was found in cases handled by OM $(17.1 \%$, $274 / 1598)$ when compared to $\operatorname{NOM}(8.3 \%, 887 / 10,642)$ [3].

Kidneys that experience blunt trauma can recover completely with NOM. Even in trauma conditions accompanied by urinary extravasation and the presence of non-viable tissue, $98 \%$ of cases can be managed conservatively. Van der Wilden et al. reported that $74.8 \%$ of cases (154 patients) were offered NOM, which was successful for 142 patients. The renal unit (i.e., the kidney) was preserved in 135 of $142 \mathrm{NOM}$ patients (95.1\%). 43.5\% of NOM patients (67 of 154) returned for follow-up, and $5.97 \%$ of NOM patients (4 of 67) were reported to have persistent hematuria at follow-up, while 1 NOM patient still had poor function of the renal due to hydronephrosis. The rest did not found show long-term sequelae [18].
Two cases in our study in the high-grade renal trauma group were found to suffer from hydronephrosis due to obstruction from a previous ureteric stone. NOM was performed on both of these patients, and so far, we have found good renal function outcomes. The incidence of previous renal abnormalities in patients with renal trauma is $4.4-19 \%$. The main anomalies that are often found include hydronephrosis, cysts, tumors, and malposition. [17].

\section{Conclusion}

The majority of blunt and penetrating renal trauma that are hemodynamically stable have a good outcome when treated with NOM. The presence of injury following other intra- and extra-abdominal important organs aggravates the patient's condition and affects the prognosis.

\section{Abbreviations}

ICD-10 code: International Statistical Classification of Diseases and Related Health Problems-10; AAST: American Association of the Surgery of Trauma; NOM: non-operative management; OM: operative management; MSCT: multislice computed tomography; RBC: red blood cells; HPF: high power field; GCS: Glasgow coma scale.

\section{Acknowledgements \\ This article was presented as a poster presentation at the 17th Urological Association of Asia (UAA) Congress, 7-10 August 2019, Kuala Lumpur Conven-} tion Centre, Malaysia.

\section{Authors' contributions}

SY, MAP, and MF researched the literature and wrote the manuscript. SY, MAP, $\mathrm{KK}, \mathrm{SS}, \mathrm{RS}$, and MF operated on the patient and had the idea for this original research. SY, AMP, MAP, SS, and KK checked the manuscript and made corrections. AMP, KK, MAP, and SY provided the overall guidance and support. All authors read and approved the final manuscript.

\section{Funding}

This research received no specific grant from any funding agency in the public, commercial, or not for- profit sectors.

\section{Availability of data and material}

The datasets generated and/or analyzed during the current study are not publicly available but are available from the corresponding author on reasonable request.

\section{Competing interests}

The authors declare that they have no competing interests.

\section{Ethics approval and consent to participate}

The ethical approval was given from the medical research ethical committee of Faculty of Medicine Universitas Hasanuddin No.1068/UN464531/PP36/2019.

\section{Consent for publication}

The research was conducted ethically in accordance with the World Medical Association Declaration of Helsinki. The patients have given their written informed consent on admission to use their prospective data base and files for research work (and as it is a retrospective study on the previous patients data and records so no need for new consents).

\section{Author details}

${ }_{1}^{1}$ Division of Urology, Department of Surgery, Faculty of Medicine, Hasanuddin University, Jalan Perintis Kemerdekaan KM 11, Makassar 90245, Indonesia. 
${ }^{2}$ Department of Surgery, Faculty of Medicine, Hasanuddin University, Makassar, Indonesia.

Received: 28 May 2020 Accepted: 16 September 2020

Published online: 13 November 2020

\section{References}

1. Brandes SB, Eswara JR (2020) Upper urinary tract trauma, 12th edn. Saunders Elsevier Company, Philadelphia

2. McAninch JW (2013) Injuries to the genitourinary tract. In: Jack TFL, McAninch W (eds) Smith Tanagho's Gen. Urol., Eighteenth, The McGrawHill Companies, Singapore, pp 280-287

3. Mingoli A, La Torre M, Migliori E, Cirillo B, Zambon M, Sapienza P, Brachini $G$ (2017) Operative and nonoperative management for renal trauma: comparison of outcomes. A systematic review and meta-analysis. Ther Clin Risk Manag 13:1127-1138. https://doi.org/10.2147/TCRM.S139194

4. Patel DP, Redshaw JD, Breyer BN, Smith TG, Erickson BA, Majercik SD, Gaither TW, Craig JR, Gardner S, Presson AP, Zhang C, Hotaling JM, Brant WO, Myers JB (2015) High-grade renal injuries are often isolated in sportsrelated trauma. Injury 46:1245-1249. https://doi.org/10.1016/j.injur y.2015.02.008

5. Mangaiyarkarasi S, Thiruvasagamani B, Subhakanesh SK, Larif A, Anandan H (2017) Epidemiological analysis of trauma patients with renal injuries. Int J Sci Study 5:94-97. https://doi.org/10.17354/ijss/2017/503

6. Khan AR, Fatima N, Anwar K (2010) Pattern and management of renal injuries at Pakistan Institute of Medical Sciences. J Coll Phys Surg Pak 20:194-197

7. Rajendra B, Sharma V, Basavaraj M, Neeraj S, Nitin D, Grade V (2017) Renal injury-short and long term outcome. Open J Trauma 1:20-25. https:// doi.org/10.17352/ojt.000005

8. Chouhan JD, Winer AG, Johnson C, Weiss JP, Hyacinthe LM (2016) Contemporary evaluation and management of renal trauma. Can J Urol 23:8191-8197

9. Kitrey ND, Djakovic N, Kuehhas FE, Lumen N, Serafetinidis, Sharma DM (2018) EAU guidelines on urological trauma 2018. In: Eur. Assoc. Urol. Guidel. 2018 (ed) European Association Urology Guidelines Office, Arnhem, The Netherlands. http://uroweb.org/guideline/urological-traum a/. LK - Urological Trauma Uroweb\%7Chttp://uroweb.org/guideline/urolo gical-trauma/\%7CFG-0
10. Patel P, Duttaroy D, Kacheriwala S (2014) Management of renal injuries in blunt abdominal trauma. J Res Med Dent Sci 2:38. https://doi. org/10.5455/jrmds.2014229

11. Lee MA, Jang MJ, Lee GJ (2017) Management of high-grade blunt renal trauma. J Trauma Int 30:192-196. https://doi.org/10.20408/ jti.2017.30.4.192

12. Erlich T, Kitrey ND (2018) Renal trauma: the current best practice. Ther Adv Urol 10:295-303. https://doi.org/10.1177/1756287218785828

13. Maibom SL, Holm ML, Rasmussen NK, Germer U, Joensen UN (2019) Renal trauma: a 6-year retrospective review from a level 1 trauma center in Denmark. Scand J Urol 53:398-402. https://doi.org/10.1080/21681 805.2019.1666916

14. Guareschi BLV, Stahlschmidt CMM, Becker K, Batista MFS, Buso PL, Von Bahten LC (2015) Epidemiological analysis of polytrauma patients with kidney injuries in a university hospital. Rev Col Bras Cir 42:382-385. https ://doi.org/10.1590/0100-69912015006006

15. Voelzke BB, Leddy L (2014) The epidemiology of renal trauma. Transl Androl Urol 3:143-149. https://doi.org/10.3978/j. issn.2223-4683.2014.04.11

16. Maarouf AM, Ahmed A-F, Shalaby E, Badran Y, Salem E, Zaiton F (2015) Factors predicting the outcome of non-operative management of highgrade blunt renal trauma. Afr J Urol 21:44-51. https://doi.org/10.1016/j. afju.2014.11.006

17. Blanco Chamorro C, Garcia Ruiz R, Tejero Sanchez A, Suarez Broto MA, Serrano Frago P, Fantova Alonso A, Cabañuz Plo T, Muñoz Rivero M, Gil Sanz MJ (2016) 51 Renal trauma. Analysis in our series of conservative versus surgical treatment: management and complications. Eur Urol Suppl 15(2016):e51-e51a. https://doi.org/10.1016/S1569-9056(16)60053-2

18. Van der Wilden GM, Velmahos GC, Joseph DK, Jacobs L, Debusk MG, Adams CA, Gross R, Burkott B, Agarwal S, Maung AA, Johnson DC, Gates J, Kelly E, Michaud Y, Charash WE, Winchell RJ, Desjardins SE, Rosenblatt MS, Gupta S, Gaeta M, Chang Y, de Moya MA (2013) Successful nonoperative management of the most severe blunt renal injuries: a multicenter study of the research consortium of New England Centers for Trauma. JAMA Surg 148:924-931. https://doi.org/10.1001/jamasurg.2013.2747

\section{Publisher's Note}

Springer Nature remains neutral with regard to jurisdictional claims in published maps and institutional affiliations.

\section{Submit your manuscript to a SpringerOpen ${ }^{\circ}$ journal and benefit from:}

- Convenient online submission

- Rigorous peer review

- Open access: articles freely available online

- High visibility within the field

- Retaining the copyright to your article

Submit your next manuscript at $\boldsymbol{\nabla}$ springeropen.com 